\title{
"EU VIM PARA QUE TODOS TENHAM VIDA E VIDA EM ABUNDÂNCIA". UM ESTUDO COMPARATIVO DE ACONSELHAMENTO RELIGIOSO EM TRÊS VERTENTES RELIGIOSAS BRASILEIRAS
}

\author{
A Comparative Study of Religious Counseling in Three Religious Contexts in Brazil \\ Un Estudio Comparativo de Asesoramiento Religioso en Tres Vertientes Religiosas Brasileñas \\ DANIELle SOARES DE MACEDO \\ Camila Mariana Mesquita e Fonseca \\ ADRIANO FurTado HOLANDA
}

\begin{abstract}
Resumo: Embora o acolhimento de demandas psicológicas em seio religioso não seja, em geral, realizado por psicólogos, pode-se falar de Aconselhamento Religioso como uma modalidade de Aconselhamento Psicológico. O objetivo deste trabalho foi comparar o aconselhamento realizado em três contextos religiosos (protestantismo, catolicismo e kardecismo). Para isso, foram entrevistados dois membros de cada vertente religiosa. As três religiões comungam do apreço pelo ouvir em vez do falar e julgar, da existência de horários marcados para o atendimento e do papel do sigilo como princípio ético. As principais diferenças referemse à maneira como os tabus sociais são abordados, devido ao posicionamento moral subjacente. A tendência ao acolhimento em co-existência com a função educativa e ética da religião, o descompromisso da psicologia com a dimensão espiritual do ser humano, a possibilidade de incorporação dos "profissionais religiosos" no esforço de atendimento humanizado e holístico e a necessidade de pesquisas futuras são temas de discussão.
\end{abstract}

Palavras-chave: Aconselhamento Psicológico; Aconselhamento Religioso; Psicologia da Religião.

Abstract: Even so the shelter of psychological demands in religious environment is not, in general, carried through for psychologists, can be spoken of Religious Counseling as a modality of Psychological Counseling. The objective of this work was to compare counseling carried through in three religious contexts (protestantism, catolicism and kardecism). For this, two members of each religious source were interviewed. The three religions have in common the appraise for hearing instead of the speech and the judgement, the existence of schedules marked for the attendance and the paper of the secrecy as an ethical principle. The main differences are related to the way that the social taboos are boarded, depending of the underlying moral positioning. The trend to the shelter in coexistence with the educative and ethical function of the religion, the unconcern of psychology with the human being's spiritual dimension, the possibility of incorporation of the "religious professionals" in the effort of humanistic and holistic attendance and the necessity of future research is quarrel subjects.

Keywords: Psychological Counseling; Religious Counseling; Psychology of the Religion.

Resumen: A pesar del recibimiento de demandas psicológicas en el seno religioso no sea, en general, realizado por psicólogos, se puede decir que el Asesoramiento Religioso es una modalidad de Asesoramiento Psicológico. El objetivo de este trabajo fue comparar el asesoramiento realizado en tres contextos religiosos (protestantismo, catolicismo y kardecismo). Por eso, fueron entrevistados dos miembros de cada vertiente religiosa. Las tres religiones comulgan del aprecio por oír en vez de hablar y juzgar, de la existencia de horarios marcados para la atención y del rol del sigilo como principio ético. Las principales diferencias se refieren al modo como los tabúes sociales son abordados, debido a la postura moral subyacente. Son temas de discusión: la tendencia al recibimiento en coexistencia con la función educativa y la ética de la religión, el no comprometimiento de la psicología con la dimensión espiritual del ser humano, la posibilidad de incorporación de los "profesionales religiosos" en el esfuerzo de la atención humanizada y holística y la necesidad de investigaciones futuras.

Palabras-clave: Asesoramiento Psicológico; Asesoramiento Religioso; Psicología de la Religión.

\section{Aconselhamento Psicológico: Primeiros Passos...}

Etimologicamente, o verbo "aconselhar" tem suas raízes fincadas no latim. Segundo Houaiss \& Villar (2001), "aconselh-" é um antepositivo que remete a consult-, do verbo latino consulo, "reunir para uma deliberação, delibe- rar, discutir, examinar". A palavra Consilium é da mesma origem e significa "conselho, julgamento", no sentido de uma reunião (Cunha, 1991). No grego antigo, aconselhar é synvoulevo: syn (junto) + voulevo (considerar, determinar) (Spanoudis, 1997). Porém, o uso comum do termo foi ganhando conotações referentes a dar conselhos e/ou 
orientações, sendo - na maioria das vezes - rejeitado e visto pejorativamente devido a seu caráter diretivo.

Definido inicialmente como "uma conversa profissional" por Garret (citado por Scheeffer, 1977), com Rogers, em 1941, o aconselhamento psicológico é concebido como uma série de contatos profissionais e diretos com um indivíduo, objetivando lhe oferecer assistência no trato de aspectos pessoais e/ou relacionais, bem como na modificação de suas atitudes e comportamentos, ganhando assim um caráter mais dinâmico.

Por muito tempo, o aconselhamento permaneceu como sendo uma mera aplicação de técnicas, constituindo-se num "campo de prática ambígua, originário na demanda social e crescendo a serviço dela" (Morato, 1999, p. 77).

No Brasil, o curso do aconselhamento psicológico também seguiu roteiro semelhante. Apesar de estar vinculado à perspectiva clínica inicial - através dos Serviços de Aconselhamento Psicológico (SAP) universitários - foi sendo paulatinamente associado à questão técnica, especificamente da "entrevista psicológica", nas disciplinas de TEAP, ou Técnicas de Exame e Aconselhamento Psicológico, estando - portanto - associado ao desenvolvimento das metodologias de avaliação psicológica (Santos, 1982; Schmidt, 1987).

Esta perspectiva vem mudando na direção de uma aplicação clínica para além do setting psicoterapêutico, onde o aconselhamento passa a ser uma alternativa viável de uma clínica contextualizada em situações diversas, tais como a prevenção em saúde (como o aconselhamento em DST-Aids, por exemplo), o aconselhamento jurídico (como em Varas de Infância e Juventude, p. ex.), ou o aconselhamento em escola, dentre outros.

Rogers (1942) aponta como características necessárias ao aconselhador, sensibilidade às relações humanas, atitude receptiva, respeito pelo indivíduo e pela sua expressão de sentimentos (primando pela liberdade de qualquer tipo de coerção e pressão), "firme compreensão de si mesmo, dos seus modelos afetivos dominantes e das suas próprias limitações” (p.214), habilidade para tornar a relação terapêutica possível e afetivamente profunda, e amplos conhecimentos da Psicologia.

Uma modalidade que vem ganhando espaço, notoriedade e grande expansão é o aconselhamento religioso, principalmente a partir do desenvolvimento de um número considerável de novas igrejas, em especial do ramo pentecostal e neopentecostal, o que acabou por gerar necessidades novas, incluindo-se aqui a perspectiva do acolhimento de demandas psicológicas no seio de um ambiente religioso (Collins, 1995; Friesen, 2000; Navarro, 2004; Holanda, 2005). É nesta perspectiva que se insere o "aconselhamento pastoral" ou "aconselhamento religioso" (também chamado de "aconselhamento cristão"), como se pode observar na literatura recente (Eliason; Hanley \& Leventis, 2001; Belcher, 2004; Oppenheimer, Flannelly \& Weaver, 2004; Turton, 2004).
Podem ser apontadas algumas semelhanças entre o aconselhamento religioso, em princípio, e o aconselhamento descrito por Rogers, entre eles a necessidade de consideração positiva e incondicional, de compreensão empática e de autenticidade por parte do aconselhador (Rogers, 1942). Entretanto, os princípios éticos e educativos que estão no cerne das diversas religiões por vezes dificultam esse tipo de postura dos aconselhadores religiosos. Por outro lado, algumas semelhanças se sustentam na prática e não podemos afirmar se a semelhança se deve à própria sabedoria cultural-religiosa ou à influência direta ou indireta de Rogers.

De qualquer modo, a questão sobre a qual nos alicerçamos envolve a correlação entre o aconselhamento pastoral (aqui tomado genericamente, no sentido de abarcar as modalidades anteriormente apontadas) e a clínica psicológica (Bulkeley, 2000; Becker, 2003; Olsen, 2005; Moran, Flannelly, Weaver, Overvold, Hess, \& Wilson, 2005; Morrison, 2005). Estas relações envolvem igualmente discussões relacionadas às formas como as noções de saúde e religião se entrelaçam (Cerqueira-Santos, Koller, \& Pereira, 2004; Gall \& Grant, 2005), bem como discussões acerca da própria religiosidade contemporânea (Esperandio, 2004).

\section{Religião, Ser Humano e Psicologia}

A religião acompanha a busca de um sentido para a existência, do universo e do homem. Os pressupostos religiosos estão acima do conhecimento comum e da racionalidade pura. O homem religioso busca constante relação com o sagrado, dotando as coisas do mundo de significado simbólico (Eliade, 1965; Benkö, 1981; Macedo, 1989). As religiões estão presentes em todas as culturas e civilizações, diferindo entre si pelas formas de encarar o dito mundo superior e sua relação com os homens. Embora seja difícil encontrar um elemento comum entre as diversas religiões, pode-se dizer que todas elas trazem a idéia do sagrado.

Este caráter do "sagrado" - e do "profano" (Eliade, 1965) - remete-nos à definição clássica de Rudolf Otto com respeito à experiência do numinoso, descrita em sua obra Das Heilige (“O Sagrado”). Benkö (1981, p. 16) a descreve como "algo exterior a nós que pressentimos de certo modo, e que não podemos desenvolver plenamente em conceitos", e acrescenta dizendo que esta experiência se manifesta em dois sentimentos: "o mistério do tremendo e o mistério do fascinante". Outro elemento comum é a combinação de intelectualidade (que a torna inteligível) e a intensidade emocional (que proporciona o colorido vivencial de seus adeptos).

A crença em níveis de existência superiores à vida material, que explicariam ou dariam sentido à vida, e a regulamentação de práticas individuais ou coletivas para, de alguma forma, alcançar esse mundo superior e por meio 
dessa conexão extrair benefício, seja ele material ou espiritual, são aspectos caracterizadores das religiões.

As ciências da religião, que atualmente desenvolvemse sobremaneira, envolvem - dentre outras - a sociologia, a antropologia, a psicologia, a filosofia da religião e a fenomenologia religiosa. Florescendo no século passado, surgiram em decorrência da elaboração das "Ciências do Espírito" (Geisteswissenschaften), no esteio da sistematização dos conhecimentos sobre cultura e sociedade recémadquiridos sobre os povos primitivos e das culturas tradicionais (Benkö, 1981). Os cientistas da religião tratam o fenômeno religioso como possuindo estrutura independente, embora esteja ligado a elementos de natureza social e psicológica (Hellern, Notaker \& Gaarden, 2000).

Embora haja um número imenso de religiões pelo mundo, as três principais religiões no Brasil são o catolicismo, o protestantismo e o espiritismo, com maior quantidade de adeptos e vasta literatura para consulta.

O catolicismo foi religião oficial do Brasil por quase quatro séculos, desde a sua descoberta. Apenas no fim do século XIX, quando o regime republicano passou a vigorar, a Igreja Católica foi separada do Estado Nacional e a liberdade de culto foi instituída. Entretanto, o catolicismo continua sendo a religião majoritária no Brasil e é professado por $88 \%$ da população, de acordo com o censo de 2000, que aponta para uma população de católicos em torno de 125,5 milhões no país (Jacob, Hees, Waniez, $\&$ Brustlein, 2003).

O protestantismo chega ao Brasil por meio da influência de alemães, britânicos e norte-americanos. Há diversas formas de protestantismo, com subdivisões importantes. No Brasil, o último censo do IBGE agrupou os "protestantes" em duas categorias: os "evangélicos de missão" (que corresponderiam aos protestantes ou evangélicos tradicionais, englobando as igrejas Batista, Adventista, Luterana, Presbiteriana, Metodista, Congregacional, Menonita e Anglicana) e os "evangélicos pentecostais" (englobando denominações como a Assembléia de Deus, Congregação Cristã do Brasil, Igreja Universal do Reino de Deus, Evangelho Quadrangular, Deus é Amor, dentre outras). O primeiro grupo - dos "tradicionais" ou "de missão” - somam 8.477.068 de pessoas no Brasil; enquanto o segundo grupo - dos "pentecostais" - somam 17.733.477 fiéis declarados, perfazendo um total de 26.510.545 pessoas (Jacob, Hees, Waniez, \& Brustlein, 2003).

O sistema filosófico-religioso denominado Espiritismo/ Kardecismo tem como base a crença na reencarnação, a possibilidade de comunicação com os mortos (espíritos desencarnados) por meio da mediunidade e uma ética da caridade como caminho para a evolução espiritual, além da consideração dos homens como seres livres e absolutamente responsáveis por seus atos. Representando para Allan Kardec uma união entre ciência, religião e filosofia, o espiritismo não se ocuparia de questões dogmáticas como ocorre em outras religiões cristãs (Kardec, 1859/1998). No Brasil, os espíritas kardecistas perfazem um total de mais de 2.200.000 praticantes (Jacob, Hees, Waniez, \& Brustlein, 2003).

Os dados do Censo de 2000, realizado pelo IBGE, trouxeram ainda algumas conclusões interessantes acerca da religiosidade do brasileiro. Houve uma diminuição do percentual de católicos (embora tenha havido crescimento em números absolutos), o que significou um aumento no percentual de evangélicos e dos declarados "sem religião" (Antoniazzi, 2003).

A pesquisa que ora apresentamos optou por trabalhar com estas três grandes vertentes, dado que estas representam uma parcela significativa da população brasileira e reflete suas mais significativas afiliações religiosas.

\section{Aconselhamento Religioso}

Utilizaremos o termo "aconselhamento religioso" neste trabalho, visto que, embora o termo "pastorear" possa ser encontrado em todas vertentes cristãs, "aconselhamento pastoral” é, geralmente, referente ao atendimento realizado nas igrejas protestantes.

Segundo Leloup (2004), “therapeutes”, no grego antigo, podia apresentar dois sentidos: "servir, cuidar, render culto" e "tratar, sarar”. O autor afirma que, segundo a literatura da época, a figura do terapeuta era multifacetada, cuidando do corpo, da alma, dos deuses, das palavras e da ética. Entretanto, o terapeuta não cura, ele cuida e ajuda o vivente a tratar-se e curar-se. Em um sentido particular desta descrição, o terapeuta navega pelas paragens da espiritualidade: "é também um ser 'que sabe orar' pela saúde do outro, isto é, chamar sobre ele a presença e a energia do Vivente, pois só ele pode curar toda dor nela e com o qual ele 'coopera'” (Leloup, 2004, p. 26).

Assim, o aconselhamento religioso nasce da conjunção entre a figura de um terapeuta, que auxilia na resolução de problemas, e a figura do orientador religioso, que insere o fiel no caminho da espiritualidade. Essa forma de aconselhamento surge em campo não-psicológico, retoma a visão holística de homem e acolhe a dimensão religiosa do ser humano, muitas vezes preterida em psicoterapia.

A seguir, apresentaremos um breve apanhado sobre o aconselhamento religioso, nas três principais vertentes religiosas do Brasil (Catolicismo, Protestantismo e Espiritismo), conforme descrito pela própria literatura religiosa.

O aconselhamento religioso no protestantismo é denominado, em geral, por "aconselhamento pastoral". Friesen (2000, p. 19), pastor e psicólogo, afirma sobre o Aconselhamento Pastoral, que é antes de tudo a comunicação da palavra de Deus, o seguinte: "Não é psicoterapia, nem psicanálise, nem tampouco a tentativa de resolver problemas apenas através de conselhos". (...) "é um relacionamento interpessoal em que o conselheiro assiste ao indivíduo em sua totalidade no processo de ajustar-se melhor consigo mesmo e com seu ambiente". 
Uma outra definição deste procedimento pode ser encontrada em Farris (2005, p. 162): "De modo geral, o aconselhamento pastoral é o processo pelo qual um pastor, ou outro representante da igreja, trabalha com indivíduos, grupos ou famílias, num contexto relativamente estruturado, com um programa de conhecimento emocional, psicológico e espiritual, tentando lidar com os problemas práticos da vida, geralmente as crises".

Friesen (2000) discorre sobre a relação entre a Psicologia e o Aconselhamento Pastoral, marcando a importância daquela ao afirmar que a falta de conhecimento profissional e técnico do conselheiro pastoral não é compensada pela fé. A principal diferença estaria no fato de que o "aconselhamento pastoral baseia-se primordialmente sobre princípios bíblicos/teológicos” (p. 32). Além disso, o aconselhamento pastoral "mantém em seu rol de funções o confronto com ações pecaminosas, o convite ao arrependimento e mudança de atitudes, e a reformulação de princípios de vida de acordo com os preceitos bíblicos" (p. 33), o que difere dos objetivos da psicoterapia.

De acordo com Friesen (2000), "o aconselhamento pastoral não pode ter como único objetivo levar a pessoa a romper com Satanás e buscar a comunhão completa com Deus. O indivíduo que já possui a certeza de salvação deve ser ajudado a crescer na santificação, no viver bem, em 'plenitude e abundância de vida" (p. 26). O pastor há sempre que se questionar sobre suas motivações para o exercício do aconselhamento e sobre o objetivo de relatar experiência pessoal e sobre reações autoritárias.

Por fim, sobre a escolha do aconselhador por uma postura, Friesen (2000) entende que se deve usar uma abordagem não-diretiva até que o aconselhando tenha conquistado a certeza da aceitação incondicional e até que suas dificuldades estejam suficientemente explicadas para ele mesmo e também para o conselheiro.

$\mathrm{O}$ aconselhamento religioso no espiritismo, baseado no Evangelho Segundo o Espiritismo, é chamado de "Atendimento Fraterno". O objetivo é atender individualmente e de maneira personalizada aqueles que sofrem, utilizando para isso, o diálogo espontâneo, confidencial e privativo (Azevedo, Neves, Ferraz \& Calazans, 2000).

$\mathrm{O}$ aconselhador deve ter como ponto de partida para seu trabalho terapêutico o conhecimento sobre a imortalidade do espírito, sua sobrevivência ao túmulo e suas múltiplas oportunidades reencarnatórias.

Evitando dar às sessões a conotação de confessionário, o aconselhador procura dar à conversação um tom agradável e despido de julgamentos. O "atendimento fraterno”, segundo Azevedo, Neves, Ferraz \& Calazans (2000), é um encontro com aquele que tem qualquer tipo de carência. A proposta não é a de resolver os desafios e dificuldades daqueles que buscam atendimento, mas sim o de bem receber e orientar o aconselhando de maneira que este adquira as habilidades necessárias à sua recuperação e reestruturação, visto que o êxito da intervenção dele depende.
Juntamente ao trabalho de aconselhamento, a pessoa atendida submete-se à influência de ações fluídicas (como os passes, por exemplo), auxílio bioenergético e inspiração espiritual, para a transformação interior e harmonização da alma. A presença de bons espíritos ao longo do tratamento ajuda na modificação da estrutura psíquica dos pacientes (Azevedo, Neves, Ferraz \& Calazans, 2000, p. 17).

Quanto ao aconselhador, é necessário preparo psicológico e doutrinário, capacidade de ouvir, além de uma postura de amor incondicional por aqueles a quem atende. Os limites da atuação do aconselhamento são reconhecidos, assim como o papel que a medicina e a psicologia podem desempenhar na manutenção e restauração da saúde orgânica e psíquica. Em casos de desequilíbrio orgânico e psicológico há a recomendação para que profissionais dessas áreas da saúde sejam consultados (Azevedo, Neves, Ferraz \& Calazans, 2000).

A função do espiritismo e do atendimento fraterno seria o de facilitar uma auto-cura espiritual, tendo sempre em vista a noção de saúde como conseqüência de uma transformação moral. Propõe-se um despertar de consciência, para que não se repitam os episódios de insensatez, os erros e os eventos causadores de sofrimento e para que se aproveite a adversidade para aprendizado e aprimoramento espiritual.

No catolicismo encontramos o aconselhamento vinculado à idéia de "direção espiritual" que consiste, sobretudo, em acolher de maneira delicada, terna e amorosa aquele que necessita de ajuda, iluminando os pensamentos, incentivando o perdão e a reconciliação, a exemplo de Jesus Cristo (Comunidade Católica Shalom, 2005).

Dessa forma, é essencial manter, para com o aconselhando/orientando, uma postura misericordiosa, visto que ele por vezes traz consigo a ferida dos pecados, as cegueiras espirituais, a fé ignorante e uma compreensão limitada da realidade humana e suas adversidades (Comunidade Católica Shalom, 2005).

A literatura encontrada sobre aconselhamento no catolicismo aponta a necessidade da experiência pessoal de Deus por parte do aconselhador. Assim, recomenda-se uma rotina diária de orações, estudo da palavra de Deus (a Bíblia), vida sacramental em ordem, e participação freqüente (se possível diária) da missa e da comunhão, assim como a confissão mensal ou quando houver necessidade.

Segundo o que diz a Comunidade Católica Shalom (2005), é indispensável que o trabalho de aconselhamento seja pautado pela palavra de Deus e a doutrina da Igreja. Além disso, o aconselhador deve ter plena convicção de carrega consigo o Espírito Santo, que dirige seus dons e o orienta nas escolhas e palavras.

Nesta perspectiva, muitas problemáticas com as quais o aconselhador vai lidar são percebidas pela ótica puramente espiritual (semelhante a outras denominações), como podemos observar no exemplo do tratamento da depressão. Segundo Aquino (2004, p. 6), "embora a de- 
pressão tenha também causas biológicas, as causas principais parecem ser de fundo emocional, psicológico e espiritual", e conclui dizendo que "a psicoterapia, embora necessária, não está ao alcance de todos". Neste contexto surge o que chama de "terapia espiritual", cujo objetivo - para os que a procuram - seria que "abandonados em Deus, tenham força para redescobrir o valor da vida e vencer o problema" (p.6).

O objetivo maior seria ajudar a discernir, dentre as coisas que o mundo oferece, aquilo que é bom e cristão. Isso se aplica às atividades de lazer, nas leituras, nos meios de comunicação, no trabalho, nos estudos. É discernimento que auxilia na tomada de decisões e na resolução dos diversos problemas da vida.

Um dos aspectos que se destaca nestas perspectivas é a convicção de que podem ser utilizadas teorias e técnicas psicológicas para ajudar o indivíduo ou o grupo. Esta relação entre Psicologia e Religião, embora ainda pouco elaborada no seio das diversas denominações, merece um destaque maior. Tanto a Psicologia quanto a espiritualidade podem ser entendidas como dois universos simbólicos que usam conceitos diferentes para descrever um processo bem parecido: a construção, a percepção ou a criação de significados. Diante disto, vamos destacar a compreensão que sujeitos atuantes destas denominações têm desta relação.

\section{Objetivos: o Caminho Aberto}

Este trabalho teve como objetivo geral comparar o serviço de aconselhamento de três vertentes religiosas por meio de depoimentos decorrentes de entrevistas com alguns de seus membros.

\section{Método}

Participantes: Participaram seis membros das referidas religiões, sendo dois pastores da Igreja Batista, dois padres católicos e duas atendentes espíritas.

Instrumento: Elaborou-se um roteiro de entrevista com 17 questões, que serviu de norteadora para a tomada dos depoimentos, que se encontra em anexo (Anexo 1).

Procedimento: Todos os participantes foram entrevistados de forma semi-estruturada, com duração aproximada de 1 hora. Todas as entrevistas foram gravadas em fita K7. Todos os participantes assinaram um Termo de Consentimento Informado.

\section{Resultados}

Para melhor apresentação dos resultados, preferiu-se agrupar as perguntas do roteiro em 3 blocos: a) um primeiro bloco composto pelas seis primeiras questões (1 a 6), que abordam questões técnicas do aconselhamento; b) no segundo bloco, temos da questão 7 à 12, que tratam de questões de procedimento geral; c) no terceiro bloco, da questão 13 à 17 , que estão mais próximas à interface religião-aconselhamento.

\section{$1 .{ }^{\circ}$ Bloco}

Todos afirmaram que realizavam aconselhamento. Os padres definiram sua prática como "aconselhamento espiritual" ou "direção espiritual", os pastores nomearam como "aconselhamento pastoral" e os espíritas disseram prestar "atendimento fraterno".

Quanto ao que seria aconselhamento, trechos importantes das respostas seguem:

Padre 1: "O aconselhamento é uma ajuda espiritual, uma direção espiritual para a pessoa que procura, diante de uma questão, um problema no qual ela não consegue encontrar uma saída. (...) A gente ajuda ela entender que aquele mesmo problema que pode ser que seja enfocado de uma forma unifocal apenas, nós passamos a estudar aquele problema de uma forma mais ampla para entender outras formas de direção para aquele mesmo fato, para que ela mesma perceba."

Padre 2: "É a ajuda, o conforto que damos às pessoas quando elas têm um problema e não sabem o que fazer. Recomendamos a oração, a confiança em Jesus e paciência para lidar com as dificuldades".

Pastor 1: "Aconselhamento inclui ouvir aquilo que está incomodando ou até o que seja uma razão de prazer. Nessas ocasiões as pessoas querem uma orientação e essa orientação é o que efetivamente caracteriza o aconselhamento pastoral."

Pastor 2: "Aconselhamento é você receber pessoas necessitadas em várias áreas da vida e ajudá-las a se encontrarem, encontrarem seu caminho, sua direção (...) Aconselhamento é você se permitir ouvir as pessoas e na hora certa, você tentar conduzi-las a um porto seguro, a uma direção que elas estão precisando porque ela está meio desnorteada"

Espírita 1: "O aconselhamento nas casas espíritas, nós temos uma atividade que nós chamamos de atendimento fraterno, que é uma conversa, na verdade, em que você reservadamente conversa com uma pessoa que em geral procura a casa porque tem algum problema, alguma dificuldade. Então aconselhamento seria esse diálogo, que é um diálogo fraterno, em que você tenta orientar a pessoa, claro, dentro dos postulados, no nosso caso, da doutrina espírita."

Espírita 2: "É levar a pessoa para o auto-conhecimento, para ampliar a compreensão do momento que ela está 
vivenciando. Isso para que ela fique livre de estigmas e do misticismo e para que ela veja o problema como uma oportunidade de crescimento, sem culpabilizar o outro pela situação por que está passando. Não há convencimento de que a doutrina espírita é a verdade absoluta, existe a tentativa de ampliar a consciência da necessidade de auto-melhoramento".

Quanto ao local de realização do atendimento, os padres afirmaram ser na igreja, os pastores afirmaram realizar no gabinete pastoral e os espíritas disseram realizar em salas do centro espírita. Entretanto, há certa flexibilidade por parte dos padres e dos pastores, visto que o aconselhamento pode ocorrer em outro local (casa do aconselhando, por exemplo) em ocasiões especiais. Em relação à duração do atendimento, todos disseram ser variável, dependendo do caso, havendo atendimento prolongado para "casos mais graves”. Todos também disseram possuir um horário de atendimento, sendo que, um dos pastores e um dos padres, afirmaram não serem tão rígidos quanto a isso.

Em geral, todos atendem individualmente, mas há casos em que casais e familiares são atendidos conjuntamente, dependendo da natureza do problema. Os padres afirmaram que a dinâmica grupal é utilizada em outras ocasiões.

\section{2. ${ }^{\circ}$ Bloco}

Em relação às estratégias utilizadas, os depoentes foram unânimes em se referir à escuta. O sentido da escuta, ou seja, de "muito mais ouvir que falar" foi diversas vezes dito pelos diferentes representantes. Um dos pastores (pastor 2) também foi veemente em dizer "como nós temos a Bíblia, a palavra de Deus, o livro que nos indica tudo, a oração e a orientação do Espírito Santo. A gente recorre a isso aí...À oração, conversando com a pessoa e ás vezes a gente pede que a pessoa espere...”, referindo-se ao fato de que pede, às vezes, que a pessoa reze e pense melhor antes de tomar alguma atitude.

O segundo padre diz ser essencial "acolher a pessoa com carinho, sustentar uma posição humilde e sincera, sem querer mostrar que se é melhor ou pior. O maior exemplo é o de Jesus Cristo, que mesmo sendo filho de Deus não se escandaliza, não julga e não acha nada impossível”.

Um dos espíritas (espírita 1) afirmou a importância de se mostrar interessado pela pessoa que é atendida. A outra diz ser importante levar a pessoa a se questionar, e ver que o sofrimento às vezes funciona como uma "assepsia espiritual”, mas que viemos ao mundo para sermos felizes e isso nós conseguiremos por meio da reforma íntima.

Quanto ao sigilo, todos afirmaram que esta é importante questão ética no aconselhamento. Um dos pastores (pastor 2) afirmou: "Esse é o grande peso que o pastor carrega. Porque isso é fundamental, faz parte da ética pastoral (...) É fundamental para que ele ganhe confian- ça(...) Há uma ligação muito grande, ele chega se emocionar". O outro (pastor 1) disse que apenas quando o caso possa servir de edificação e com a permissão da pessoa, sem citar nomes, é que ele torna pública a história. As aconselhadoras espíritas afirmaram que quando o caso é muito grave, comunicam ao diretor do departamento de orientação mediúnica. Ambos os padres disseram manter sigilo absoluto.

Todos disseram que encaminham para profissionais de saúde quando percebem a necessidade e relataram casos de encaminhamentos bem-sucedidos. Quanto à situação em que percebe a necessidade do encaminhamento, o padre 1 afirmou que o faz "quando a pessoa nos dá certos indícios de problemas neurológicos, problemas emocionais muito graves, muito sérios, de depressão profunda...(...) Muitas pessoas chegam lá achando que seu problema é espiritual, mas seu problema não é espiritual, o problema é psicológico, a gente faz com que a pessoa perceba.”.

O pastor 1 afirma que percebe os limites da autoridade do ministério pastoral no aconselhamento ("A humildade é o reconhecimento do limite pessoal ou do limite da função em que se está"). Já o pastor 2 disse: "Quando vejo que a coisa não é só espiritual, sintomas de esquizofrenia, distúrbios que são psicológicos...Você nota, você também não consegue sucesso, não vai conseguindo sucesso...”.

A espírita 1 exemplificou falando de casos com depressão. A espírita 2 faz o encaminhamento quando a pessoa mostra vontade de se tratar e acredita na eficácia do método terapêutico. Procura mostrar às pessoas que há situações que fogem a seu controle e que não somos auto-suficientes e muitas vezes precisamos de ajuda profissional para corrigirmos algum distúrbio emocional, orgânico ou espiritual.

Todos disseram recorrer a serviços de orientação. Um dos pastores (pastor 2) evidenciou a necessidade pessoal: "Quando você tem um problema que você acha difícil de solucionar com membros da igreja. Sobretudo, quando o problema é com um colega. Eu tenho pedido e me sinto feliz em fazer isso". O outro pastor e a espírita 1 referiram ao serviço de supervisão, isto é, aconselhamento relativo à dificuldades na execução do aconselhamento.

A segunda espírita diz que "quando o orientador faz o curso é orientado a periodicamente reequilibrar suas energias, se afastar do trabalho quando estiver espiritualmente desequilibrado. Para cada grupo há um dirigente capacitado para resolver os problemas que os orientadores não se sentem aptos a resolver".

De acordo com o segundo padre, "um sacerdote procura outro para as suas confissões e aos formadores e profissionais de psicologia quando há problemas de ordem emocional, ligados ou não à direção espiritual". Segundo ele, é comum a busca de aconselhamento para ajudar os padres a lidarem melhor com a questão da sexualidade e do celibato.

Os casos mais comuns foram semelhantes para todos os participantes, incluindo problemas de relacionamen- 
tos conjugais, dificuldades com os filhos, problemas ligados à homossexualidade, indecisão vocacional, alcoolismo, drogadicção em geral, problemas de administração financeira, depressão, estresse. A espírita 1 relatou que, de acordo com a Federação Espírita Brasileira e com a União Espírita do Estado de São Paulo, “de 70 a 80\% das pessoas que procuram os centros espíritas têm problemas familiares". A segunda espírita acrescenta, ainda, casos de perda de entes queridos e rompimento de relações amorosas como freqüentes.

\section{3. ${ }^{\circ}$ Bloco}

Tanto os padres quanto as espíritas afirmaram que a demanda vem do aconselhando. Os pastores disseram que a demanda é via de mão dupla, isto é, tanto as pessoas procuram quanto os pastores podem ir ao seu encontro. $\mathrm{O}$ pastor 1 disse que "é mais comum as pessoas procurarem o pastor. Entretanto se percebe a necessidade e a pessoa não procura, eu tomo essa iniciativa porque a visão que um pastor tem do seu rebanho permite a ele muitas vezes identificar a necessidade." O pastor 2 afirmou: "O pastor vai atrás da ovelha, é a ovelha ferida que nós chamamos, está doente, carente por causa das pressões do mundo. Ele vai atrás da ovelha ferida, da ovelha caída”

No que se refere ao suicídio, o padre 1 relatou fazer uma "oração de libertação" e considerou que "o suicídio é uma doença da alma”. Já o segundo padre diz que nesses casos tenta, com carinho e paciência, convencer a pessoa de que "ela tem valor, de que ela tem algo de bom, que ela tem virtudes".

O pastor 1 afirmou não ter tido nenhuma experiência como essa, mas "caso tivesse, não me apavoraria, não me mostraria surpreso (...) pessoa está em um extremo de desprezo pela vida ou de abalo emocional e talvez tenha procurado um conselheiro em busca de uma referência de firmeza.”. Já o segundo pastor disse que já teve experiência e que "não tem um método, pode até ser que do ponto de vista psicológico haja alguma forma, mas gente ora, conversa, a gente tenta dissuadi-lo, tentando aconselhar".

A espírita 1 disse que já teve algumas experiências neste sentido e que "tenta orientar dentro dos postulados da doutrina espírita (...) A gente conversa, tenta encaminhar para o tratamento ou para o acompanhamento psicológico porque a pessoa precisa de um acompanhamento (...). Como a gente não sabe se a aquela pessoa vai voltar, o que vai acontecer, eu particularmente, falo para ela as conseqüências do suicido no plano espiritual que é um dos sofrimentos mais terríveis que existe.”.

A espírita 2 procura conscientizar a pessoa de que os problemas não desaparecem após a morte, que eles precisam ser enfrentados de maneira que possamos evoluir. Além disso, ela encaminha a pessoa para um grupo de apoio psicológico, que existe na própria casa (Comunhão Espírita). Com exceção do pastor 2, que relatou questões de assassinato, e da espírita 2, que apontou o problema de drogadicção como de difícil intervenção, os outros afirmaram que não havia nenhuma questão de difícil abordagem. $\mathrm{O}$ padre 1 disse: "ao se deparar com um problema muito grave, depois a gente recorre à oração, pede a Deus, quando menos a gente percebe vem uma resposta diante de nós". E o pastor 1 afirmou que não poderia haver tabus porque "a igreja está aberta para todos, embora não para tudo”.

Quanto à literatura suporte para a prática, o padre 1 disse: "quando nós sacerdotes somos formados, nós estudamos também essa matéria do aconselhamento. Então nós estudamos psicologia.”. E que a psicologia era importante em casos, por exemplo que "uma pessoa vem contar caso que a outra pessoa fez, mas ela não entende também que tem um fator de influência na situação". O pastor 1 reclamou da escassez de literatura, enquanto o pastor 2 mostrou diversos livros, inclusive o livro de Ruth Scheeffer (Aconselhamento Psicológico), bastante conhecido dos alunos de graduação em Psicologia.

A espírita 1 disse que "existe um livro editado pela Federação Espírita Brasileira que chama 'Orientação aos Centros Espíritas' e dentro deste livro tem a orientação de como fazer este atendimento fraterno" e que há também cursos específicos sobre o atendimento fraterno nas casas espíritas. Além disso, a espírita 2 apontou a necessidade que o orientador tem de ler o máximo possível das obras espíritas e tudo o que se relacione a aconselhamento, de estar sempre estudando e se capacitando para o exercício de sua tarefa (cita os livros de Joana de Ângelis, que faz uma ponte entre o espiritismo e a psicologia).

E, por fim, com relação aos tabus sociais, o primeiro padre afirmou: "nós tratamos na ótica cristã, nós procuramos visualizar na forma que Cristo nos pediu que fizéssemos (...) Jamais marginalizá-los ou recriminá-los [homossexuais] ou oprimi-los, mas fazer que ele veja esta questão de outro lado (...) Nós orientamos para que eles possam ter uma vida sexual de forma ser o mais santa." Com relação à "vida sexual santa", ele afirmou que não deveria ser exclusividade dos homossexuais, mas também prática dos heterossexuais.

O segundo padre afirmou que "tratar dessas questões é complicado, porque não sabemos suas causas. Não podemos tomar a posição de condenação. Quando as pessoas são conscientes da necessidade de mudar encaminhamos para um tratamento. Quando elas não querem, não impomos nada. Mas nesse caso é mais grave, porque é até falta de humildade se a pessoa não reconhece que precisa mudar. A igreja não deve tratar mal nem discriminar essas pessoas, mas não pode apoiar movimentos a favor porque seria tratar como normal algo que não é normal".

Já o pastor 1 disse: "qualquer desvio moral como o homossexualismo, a pedofilia tem cura sim. E eu entendo que a educação começa em fazer com que a pessoa se sinta valorizada.", enquanto o pastor 2 relatou dificuldades em relação à homossexualidade e um caso de conversão, isto é, de "ex-homossexual". 
A espírita 1 disse: "nós tratamos do conflito da pessoa, não da homossexualidade porque homossexualidade não é doença, é uma tendência que a pessoa apresenta, dentro da doutrina espírita explicada por outros motivos. Então, como o espírito não tem sexo, nós não temos muitos problemas com a homossexualidade (...) assim, casos graves como prostituição, nós tratamos mais os conflitos das pessoas, sem julgar a pessoa. Nós não estamos lá para julgar ninguém, nós estamos lá para esclarecer e consolar, que são os objetivos da doutrina espírita".

Segundo a segunda espírita "essas pessoas são encaminhadas a um apoio psicológico, mas apenas quando se sentem perturbados ou em conflito existencial. A doutrina espírita não vê a homossexualidade como desvio, pois assim como você nasceu moça nesta vida, pode nascer rapaz na próxima e carregar fortes tendências da vida anterior. Algumas vezes essas pessoas têm uma moral sexual de certa forma mais correta que pessoas heterossexuais".

\section{Discussão}

A partir dos resultados encontrados foi possível perceber que existem mais semelhanças que diferenças entre as práticas do aconselhamento no contexto religioso. Dentre as convergências podemos apontar: a utilização de horários e locais razoavelmente fixos de atendimento, o fato de todos atenderem individualmente (de preferência) e a manutenção do sigilo como pressuposto básico (em casos extremos, as espíritas recorrem à supervisão dos dirigentes do trabalho). Todos afirmaram que encaminham casos para atendimento médico-psicológico quando percebem estarem fora de seu campo de atuação e que recorrem a serviços de orientação (por questões pessoais e/ou para supervisão do trabalho) e por fim, a primazia da escuta e do acolhimento, ou seja, a preferência pelo ouvir e acolher em detrimento do falar e julgar (grifo nosso).

A flexibilidade de horário e local, que poderiam ser indicadores da prática de aconselhamento psicológico como alternativa à psicoterapia tradicional não foram totalmente confirmadas pelos relatos dos participantes. Isto talvez porque o aconselhamento religioso já foi institucionalizado e incorporado ao rol de atividades realizadas nas diversas religiões.

Uma das divergências encontradas relaciona-se ao fato de que para padres e espíritas a demanda é externa, enquanto que para os pastores a situação de aconselhamento pode surgir tanto do aconselhando quanto do aconselhador.

As outras diferenças situam-se principalmente em relação aos tabus sociais e ao suicídio. Embora todos apontem para uma postura de não-julgamento e não-condenação, o aconselhamento difere muito nestas questões. Os pastores defendem a conversão dos homossexuais (considerando a homossexualidade como desvio moral) e a possibilidade de cura, alegando que "a igreja está aberta para todos e não para tudo".
Já os católicos demonstraram uma posição mais flexível, considerando inclusive a permanência da orientação sexual e vida religiosa concomitante. A perspectiva moral subjacente, no entanto, se expressa sutilmente. Podemos percebê-la na fala do padre 2, em que apresenta a sexualidade no mesmo plano dos vícios morais: "Quando elas não querem, não impomos nada. Mas nesse caso é mais grave, porque é até falta de humildade se a pessoa não reconhece que precisa mudar. A igreja não deve tratar mal nem discriminar essas pessoas, mas não pode apoiar movimentos a favor porque seria tratar como normal algo que não é normal" (grifos nossos).

Por fim, parece que pelo fato das espíritas atribuírem explicações à homossexualidade que transcendem a vida presente, essa manifestação da sexualidade pode ser percebida com mais naturalidade e menos culpabilização do indivíduo.

Em relação ao suicídio, as espíritas sustentaram um discurso mais moral e diretivo, apontando qual comportamento seria adequado. Enquanto os pastores e padres disseram rezar pela pessoa, acolher o sofrimento e conscientizar a pessoa de seu valor no mundo, as espíritas posicionaram-se no sentido de informar, dentro da doutrina espírita, as conseqüências negativas do suicídio e de tentar levar o aconselhando a enfrentar seus problemas de outra forma que não essa.

É peculiar a este tipo de serviço, um híbrido entre psicologia e religião, conforme visto nos relatos, a co-existência da tendência de acolhimento e amparo, inclusive seguindo o modelo de "pastor de ovelhas" do próprio Cristo, onde sua figura é associada à idéia de "médico das almas" (Aquino, 2004) e a função educativa e ética da religião e direcionamento espiritual. Para Hellern, Notaker \& Gaarder (2000), as religiões, portanto, não fazem distinção entre a dimensão ética e religiosa. Isto pode ser percebido com relação à homossexualidade, para os pastores e padres, em que uma orientação sexual é vista como desvio moral ou doença passível de cura.

Já no espiritismo esse conflito ficou mais claro em relação ao suicídio, em que a não-diretividade vai até onde começa a possibilidade de auto-extermínio. Há, neste sentido, expressão clara da função educativa da religião.

Assim, embora todos afirmem indiretamente os pressupostos de um aconselhamento do tipo rogeriano (com a presença de elementos tais como escuta ativa, empatia, consideração incondicional, etc.), na prática, talvez seja mais difícil a sua realização plena, em virtude da atmosfera religiosa e moral que caracteriza o atendimento.

Este campo, em plena expansão, pode estar se nutrindo do descaso e descompromisso da psicologia científica e até mesmo da psicologia clínica, com a dimensão espiritual do ser humano. O psicólogo parece evitar ou esquecer que o ser humano é em essência espiritual, além de biopsicossocial. Na ausência da Psicologia, líderes espirituais com alguma perspicácia psicológica atendem uma demanda que, embora não se restrinja ao campo de ação da Psicologia, é também de sua alçada. 
Como a interdisciplinaridade se fortifica tendo como objetivo a atenção global a todas as dimensões humanas, a inclusão de mais uma dimensão, a espiritual, incitanos a pensar na incorporação dos "profissionais religiosos" no esforço de atendimento humanizado e holístico ao ser humano.

O estudo mais aprofundado da Psicologia por parte dos aconselhadores religiosos poderia auxiliar na distinção entre a simples utilização de critérios diagnósticos socialmente difundidos pela mídia e pelo conhecimento popular (p.ex: sinais de hiperatividade, depressão, estresse, etc.) e os indicadores de transtornos clínicos reais, severos ou não. Assim, a prática do encaminhamento poderia tornar-se mais eficiente e coerente com as necessidades dos aconselhandos. Um dos pastores relatou a necessidade de encaminhamento em casos de esquizofrenia, mas não se sabe ao certo o que seria considerado - por estes aconselhadores - como sinal patognomônico desta síndrome e qual o limite entre fenômeno espiritual e doença mental.

Sendo assim, o aconselhamento religioso aparece como uma prática importante a ser considerada, dentro de um contexto de saúde mental. Uma maior aproximação da ciência psicológica destes contextos religiosos surge como possibilidade real para a compreensão de inúmeros fenômenos psicopatológicos. Além disso, a forma como as diversas denominações religiosas lidam com o fenômeno psicopatológico ainda é uma incógnita. A relação entre psicopatologia e vivência religiosa é objeto de um projeto de pesquisa mais amplo, em desenvolvimento, por uma equipe que inclui os autores deste trabalho.

Sugere-se para pesquisas futuras a comparação da literatura de aconselhamento com a prática que vem sendo exercida e a comparação da atuação inter-religiosa, ou seja, entre membros de uma mesma religião. Além disso, é de fundamental importância maior conhecimento sobre a distinção entre quadros psicopatológicos e fenômenos espirituais, tanto na ótica religiosa quanto na psicológica.

\section{Referências Bibliográficas}

Antoniazzi, A. (2003). As Religiões no Brasil Segundo o Censo de 2000, Rever - Revista de Estudos da Religião [online], n. 2, p. 75-80, Disponível na World Wide Web: http://www. pucsp.br/rever/rv2_2003/p_antoni.pdf.

Aquino, F. (2004). A Luta contra a Depressão, Lorena: Editora Cléofas.

Azevedo, G.; Neves, J.; Ferraz, J. \& Calazans, N. (2000). Atendimento Fraterno. Salvador: Livraria Espírita Alvorada.

Becker, M.C. (2003). Aconselhamento Pastoral na Depressão: Uma análise psico-teológica do aconselhamento pastoral diante da depressão, Dissertação de Mestrado em Ciências Médicas, Faculdade de Ciências Médicas da Universidade de Campinas, Campinas.
Belcher, J.R. (2004). Religious education and pastoral counseling: The classical pentecostal experience, Pastoral Psychology, v. 53, n. 2, November, p. 97-106.

Benkö, A. (1981). Psicologia da Religião, São Paulo: Edições Loyola.

Bulkeley, K. (2000). Dream interpretation: practical methods for pastoral care and counseling, Pastoral Psychology, v. 49, n. 2, November, p. 95-104.

Cerqueira-Santos, E.; Koller, S.H. \& Pereira, M.T.L.N. (2004). Religião, saúde e cura: um estudo entre neopentecostais, Psicologia, Ciência e Profissão [online], 24(3):82-91 [citado 20 setembro 2005]. Disponível na World Wide Web: http://www.revistacienciaeprofissao.org./artigos/24_03/ pdfs/24.3.10.pdf.

Collins, G.R. (1995). Aconselhamento Cristão, São Paulo: Edições Vida Nova.

Comunidade Católica Shalom, disponível na World Wide Web em: www.comunidadecatolicashalom.org.br [Acessado em 20 Abril 2005].

Cunha, A G. (1991). Dicionário Etimológico Nova Fronteira da Língua Portuguesa, Rio de Janeiro: Nova Fronteira.

Eliade, M. (1965). Le sacré et le profane, Paris: Gallimard.

Eliason, G.T.; Hanley, C. \& Leventis, M. (2001). The role of spirituality in counseling: four theoretical orientations, Pastoral Psychology, v. 50, n. 2, p. 37-56.

Esperandio, M.R.G. (2004). A (est)ética do cuidado e religiosidade contemporânea: a igreja universal do reino de Deus em perspectiva, III Simpósio de Aconselhamento e Psicologia Pastoral, São Leopoldo, Escola Superior de Teologia. Disponível na World Wide Web: http://www. colegiobatista.org.br/portaldoensinoreligioso/artigos/estetica.pdf

Farris, J.R. (2005). Aconselhamento psicológico e espiritualidade, Em Mauro Martins Amatuzzi (Org.). Psicologia e Espiritualidade [p. 161-172]. São Paulo: Paulus.

Friesen, A. (2000). Cuidando do ser: treinamento em aconselhamento pastoral, Curitiba: Ed.Evangélica Esperança.

Gall, T.L. \& Grant, K. (2005). Spiritual disposition and understanding illness, Pastoral Psychology, v. 53, n. 6, July, p. $515-533$.

Hellern, V.; Notaker, H. \& Gaarder, J. (2000). O Livro das Religiões. São Paulo: Cia das Letras.

Holanda, A.F. (2005). Mysterium tremendum - psicologia da religião e a questão da psicopatologia. Anais do XI Encontro Goiano da Abordagem Gestáltica: Goiânia, p. 53-67.

Houaiss, A. \& Villar, M.S. (2001). Dicionário Houaiss da Língua Portuguesa, Rio de Janeiro: Objetiva.

Jacob, C.R.; Hees, D.R.; Waniez, p. \& Brustlein, V. (2003). Atlas de Filiação Religiosa e Indicadores Sociais no Brasil, Rio de Janeiro: PUC-Rio/São Paulo: Loyola. 
Kardec, A. (1859/1998). O que é o espiritismo: noções elementares do mundo invisível pelas manifestações dos espíritos. São Paulo: Lake.

Leloup, J-Y. (2004). Cuidar do ser: Fílon e os terapeutas de Alexandria. Petrópolis: Vozes.

Macedo, C.C. (1989). A imagem do eterno: religiões no Brasil. São Paulo: Moderna.

Moran, M.; Flannelly, K.J.; Weaver, A.J.; Overvold, J.A.; Hess, W. \& Wilson, J.C. (2005). A study of pastoral care, referral, and consultation practices among clergy in four settings in the New York City Area, Pastoral Psychology, v. 53, n. 3, January, p. 255-266.

Morato, H. T. (1999). Aconselhamento psicológico: uma passagem para a transdiciplinariedade. Em H.T.Morato (Org.), Aconselhamento Psicológico Centrado na Pessoa: novos desafios. São Paulo: Casa do Psicólogo.

Morrison, B.T. (2005). Stewardship models of pastoral care, counselling and supervision: the commonians meet ricoeur at worship, Pastoral Psychology, v. 53, n. 5, May, p. 435-446.

Navarro, R.R.O. (2004). Uma nova vida com Jesus Cristo: um estudo sobre psicoterapia religiosa cristã. Brasília: Thesaurus.

Olsen, R. A. (2005). Free will and therapeutic change, Pastoral Psychology, v. 53, n. 3, January, p. 267-279.

Oppenheimer, J.E.; Flannelly, K.J. \& Weaver, A.J. (2004). A comparative analysis of the psychological literature on collaboration between clergy and mental-health professionals-perspectives from secular and religious journals: 1970-1999, Pastoral Psychology, v. 53, n. 2, November, p. 153-162.

Rogers, C. (1942). Psicoterapia e consulta psicológica. Lisboa: Moraes Editores.

Santos, O.B. (1982). Aconselhamento psicológico e psicoterapia, São Paulo: Pioneira.

Scheeffer, R. (1977). Aconselhamento psicológico: teoria e prática. São Paulo: Atlas.

Schmidt, M.L.S. (1987). Aconselhamento psicológico: questões introdutórias, Em Rachel L.Rosenberg (Org.), Aconselhamento psicológico centrado na pessoa, São Paulo: E.P.U.

Spanoudis, S. (1997). A tarefa do aconselhamento e orientação a partir da daseinanalyse, Daseinanalyse, n. 1, 2 \& 4, pp. 56-62.

Turton, D.W. (2004). Expectations of counselling: a comparison between evangelical christians and non-evangelical christians, Pastoral Psychology, v. 52, n. 6, July, p. 507-517.

\section{Anexo}

01. Você faz aconselhamento?

02. O que é aconselhamento?

03. Em qual local o aconselhamento é realizado?

04. Qual a duração do aconselhamento?

05. Há algum horário reservado para o aconselhamento?

06. O aconselhamento é feito individualmente ou em grupo?

07. Que estratégias você utiliza na condução do aconselhamento?

08. Como é a questão do sigilo?

09. Você encaminha a pessoa que busca o aconselhamento para profissionais da saúde (p. ex. psicólogos)?

10. Se encaminha, quando você percebe que o encaminhamento se faz necessário?

11. Existe serviço de aconselhamento para o aconselhador?

12. Quais são os casos mais comuns?

13. De onde vem a demanda: do aconselhador ou do aconselhando?

14. Houve algum caso em que a pessoa que buscou o aconselhamento estivesse pensando em suicidar? Se sim, o que você fez?

15. Há alguma questão que você não se sente à vontade para tratar no aconselhamento?

16. Há literatura de orientação para a prática?

17. Como são abordados tabus sociais como homossexualidade e pedofilia?

Danielle Soares de Macedo - Graduada em Psicologia pela Universidade de Brasília. Email: danis_macedo@yahoo.com.br.

Camila Mariana Mesquita e Fonseca - Aluna de Graduação da Universidade de Brasília. Email: camilamarianam@yahoo.com.br.

Adriano Furtado Holanda - Doutor em Psicologia, Professor da Universidade Federal do Paraná. Email: aholanda@yahoo.com.

Recebido em 20.04.2007 Aceito em 15.08.07 